\title{
Band Anticrossing in Highly Mismatched Group II-VI Semiconductor Alloys
}

\author{
Kin Man Yu*, J. Wu*+, W. Walukiewicz*, J. W. Beeman*, J. W. Ager*, E. E. Haller*+, \\ I. Miotkowski**, and A. Ramdas** \\ * Materials Sciences Division, Lawrence Berkeley National Laboratory, Berkeley, CA \\ 94720 \\ ${ }^{+}$Department of Materials Sciences and Mineral Engineering, University of California, \\ Berkeley, California 94720 \\ ** Department of Physics, Purdue University, West Lafayette, Indiana 47907
}

\begin{abstract}
We have successful synthesized highly mismatched $\mathrm{Cd}_{1-y} \mathrm{Mn}_{y} \mathrm{O}_{x} \mathrm{Te}_{1-x}$ alloys by high dose implantation of $\mathrm{O}$ ions into $\mathrm{Cd}_{l-y} \mathrm{Mn}_{y}$ Te crystals. In crystals with $y>0.02$, incorporation of $\mathrm{O}$ causes a large decrease in the band gap. The band gap reduction increases with $y$; the largest value observed is $190 \mathrm{meV}$ in O-implanted $\mathrm{Cd}_{0.38} \mathrm{Mn}_{0.62} \mathrm{Te}$. The results are consistent with the band anticrossing model which predicts that a repulsive interaction between localized states of $\mathrm{O}$ located above the conduction band edge and the extended states of the cond uction band causes the band gap reduction. A best fit of the measured band gap energies of the $\mathrm{O}$ ion synthesized $\mathrm{Cd}_{1-y} \mathrm{Mn}_{y} \mathrm{O}_{x} \mathrm{Te}_{1-x}$ alloys using the band anticrossing model for $y<0.55$ suggests an activation efficiency of only $\sim 5 \%$ for implanted $\mathrm{O}$ in $\mathrm{Cd}_{l-y} \mathrm{Mn}_{y} \mathrm{Te}$.
\end{abstract}

Keyword: implantation, band anticrossing, highly mismatched alloys, photoreflectance Contact author: Kin Man Yu, MS2-200, Lawrence Berkeley National Laboratory, 1 Cyclotron Road, Berkeley, CA 94720. Tel: (510)486-6656, FAX: (510)486-5530, email: KMYu@lbl.gov 


\section{INTRODUCTION}

Group III- $\mathrm{N}_{x}-\mathrm{V}_{1-x}$ alloys (e.g. $\mathrm{GaN}_{x} \mathrm{As}_{1-x}$ ) in which a small amount (up to $\sim 5 \%$ ) of the electronegative $\mathrm{N}$ substitutes the more metallic column V element, have been extensively studied in recent years because of their unusually large band gap bowing. ${ }^{1-7}$ The strong dependence of the band gap on the $\mathrm{N}$ content $(\sim 150 \mathrm{meV}$ for $x \sim 0.01$ in $\mathrm{GaN}_{\mathrm{x}} \mathrm{As}_{1-\mathrm{x}}$ ) has made these diluted III-V nitrides important materials for a variety of applications, including long wavelength optoelectronic devices ${ }^{8,9}$ and high efficiency hybrid solar cells. ${ }^{10,11}$

The unusual properties of the III- $\mathrm{N}_{x}-\mathrm{V}_{1-x}$ alloys can be well explained by the recently proposed band anticrossing (BAC) model. ${ }^{12,13}$ In this model a repulsive interaction between the localized nitrogen states, which are located above the conduction band edge, and the extended states of the host semiconductor matrix splits the conduction band of the matrix semiconductor into two subbands. The dispersion relations for the upper and lower conduction subbands are given by:

$$
E_{ \pm}(k)=\frac{1}{2}\left[E_{N}+E_{M}(k) \pm \sqrt{\left(E_{N}-E_{M}(k)\right)^{2}+4 C_{N M}^{2} x}\right]
$$

where $\mathrm{E}_{\mathrm{N}}$ is the energy of the $\mathrm{N}$ level, $E_{M}(k)$ is the dispersion relation for the host semiconductor matrix, and $C_{N M}$ is the matrix element describing the coupling between $\mathrm{N}$ states and the extended states. For $\mathrm{GaN}_{x} \mathrm{As}_{1-x}$, the downward shift of the lower subband E can account well for the reduction of the fundamental band gap using a value of $\mathrm{E}_{\mathrm{N}}=1.65 \mathrm{eV}$ above the valence band maximum derived from PL measurements in Ndoped GaAs ${ }^{14}$ and from fitting the data to obtain $C_{N M}=2.7 \mathrm{eV} \cdot{ }^{12,13}$ Moreover, the BAC model also predicts a considerable flattening of the lower subband near its minimum, resulting in a large increase of the electron effective mass. ${ }^{13,15}$ 
We have demonstrated recently that the BAC model applies to not only the band modification in III- $\mathrm{N}_{x}-\mathrm{V}_{1-x}$ alloys but also to a broad class of highly mismatched semiconductor alloys (HMA) in which the metallic anions are partially replaced by more electronegative atoms. ${ }^{16}$ Other examples of the highly mismatched alloys are II-VI alloys such as $\mathrm{ZnS}_{x} \mathrm{Te}_{1-x}$ and $\mathrm{ZnSe} \mathrm{Te}_{1-x}$ alloys in which more electronegative $\mathrm{S}$ or Se partially substitute more metallic Te atoms. ${ }^{16}$ The BAC model suggests that the strength of the anticrossing interaction in HMAs depends on the electronegativity mismatch, therefore, one can anticipate it to be particularly pronounced in group $\mathrm{II}-\mathrm{O}_{x}-\mathrm{VI}_{1-x}$ alloys in view of the very highly electronegative $\mathrm{O}$ atoms substituting the significantly more metallic column VI elements. ${ }^{16}$ However, the incorporation of a large concentration of oxygen, although it is frequently present in II-VI compounds as an impurity, has proven to be technically challenging. Previously we have demonstrated the formation of III- $\mathrm{N}_{x}-\mathrm{V}_{1-x}$

alloys by $\mathrm{N}$ implantation in III-V materials. ${ }^{17-19}$ In this work we report on the successful formation of $\mathrm{Cd}_{1-y} \mathrm{Mn}_{y} \mathrm{O}_{x} \mathrm{Te}_{1-x}$ quaternaries by $\mathrm{O}$ implantation in $\mathrm{Cd}_{1-y} \mathrm{Mn}_{y} \mathrm{Te}$ crystals.

\section{EXPERIMENTAL}

Single crystal $\mathrm{Cd}_{l-y} \mathrm{Mn}_{y} \mathrm{Te}(0<y<0.65)$ ternaries were grown by the vertical gradient freezing technique.$^{20}$ Multiple energy $(30,80$ and $160 \mathrm{keV}) \mathrm{O}^{+}$implantation was carried out to form $\sim 0.3 \mu \mathrm{m}$ thick $\mathrm{Cd}_{l-y} \mathrm{Mn}_{y} \mathrm{O}_{x} \mathrm{Te}_{1-x}$ layers with relatively constant $\mathrm{O}$ concentrations of $\sim 2.5 \times 10^{20}$ and $\sim 5 \times 10^{20} \mathrm{~cm}^{-3}$, corresponding to $\mathrm{O}$ mole fractions of 0.027 and 0.054 , respectively. Hereafter these two sets of samples will be referred to as the low dose and high dose samples. In order to remove the implant damage and "activate" the implanted $\mathrm{O}$ atoms, the implanted samples were subjected to rapid thermal annealing (RTA) for $10 \mathrm{~s}$ at temperatures ranging from 300 to $800^{\circ} \mathrm{C}$.

Band gaps of the synthesized alloys were measured using photomodulated reflectance $(\mathrm{PR})$ spectroscopy at room temperature. Radiation from a 300W halogen 
tungsten lamp dispersed by a $0.5 \mathrm{~m}$ monochromator was focused on the samples as a probe beam. A chopped HeCd laser beam $(\lambda=4420 \AA)$ provided the photomodulation. PR signals were detected by a Si photodiode using a phase-sensitive lock-in amplification system. The values of the band gap and the line width broadening were determined by fitting the PR spectra to the Aspnes third-derivative functional form. ${ }^{21}$

\section{RESULTS AND DISCUSSION}

Figure 1 shows the PR spectra from three $\mathrm{Cd}_{l-y} \mathrm{Mn}_{y}$ Te samples (with $\mathrm{y}=0.01-0.19$ ) as-grown and implanted with low dose O-implanted after RTA at $600^{\circ} \mathrm{C}$. Significant band gap reductions $(\Delta E)$ are observed in the samples with $y=0.043$ and 0.19 . In contrast, in the sample with the lowest Mn content, $y=0.017$, only a small band gap reduction of the order of $10 \mathrm{meV}$ is observed. In fact, in the case of $\mathrm{O}$ implantation in CdTe crystals (not shown), no band gap reduction can be observed after annealing at temperatures higher than $400^{\circ} \mathrm{C}$. We believe that the band gap reduction in the $\mathrm{O}$ implanted $\mathrm{Cd}_{l-y} \mathrm{Mn}_{y}$ Te crystals is the result of $\mathrm{O}$ incorporation in the Te sublattice.

We clearly observe that $\mathrm{Mn}$ leads to increased stability of substitutional $\mathrm{O}$ in $\mathrm{Cd}_{l \text { - }}$ ${ }_{y} \mathrm{Mn}_{y} \mathrm{Te}$. We believe that the presence of $\mathrm{Mn}$ enhances the incorporation of $\mathrm{O}$ on the Te sublattice, possibly due to the formation of relatively strong Mn-O bonds. For samples with a Mn mole fraction of 0.19 implanted with $2.7 \%$ of $\mathrm{O}$, a $\Delta E$ as large as $60 \mathrm{meV}$, which remains stable up to an annealing temperature of $800^{\circ} \mathrm{C}$, is observed.

The possibility that the band gap reduction is due to implantation damage and/or the high temperature annealing has also been investigated. PR measurements on as-grown $\mathrm{Cd}_{l-y} \mathrm{Mn}_{y} \mathrm{Te}$ samples subjected to annealing to $800^{\circ} \mathrm{C}$ showed no band gap shift. Several $\mathrm{Cd}_{l-y} \mathrm{Mn}_{y}$ Te crystals with $y=0$ and 0.2 were implanted with $\mathrm{Ne}$ and $\mathrm{Cl}$ ions to doses chosen to create implant damage profiles comparable to the low dose O-implanted samples . ${ }^{22}$ These $\mathrm{Cd}_{l-y} \mathrm{Mn}_{y}$ Te crystals with no implanted $\mathrm{O}$ did show a band gap 
reduction that was as large as $45 \mathrm{meV}$. However, at the temperatures used to activate the O-implanted samples, i.e., $\mathrm{T}>600^{\circ} \mathrm{C}$, this damage-induced band gap reduction decreased to $<10 \mathrm{meV}$ (see inset in Fig. 3). We therefore conclude that the observed band gap reductions in the $\mathrm{O}$ implanted samples are not caused by lattice damage.

As the implanted $\mathrm{O}$ dose increases we observed a corresponding increase in $\Delta E$ in an O-implanted $\mathrm{Cd}_{1-y} \mathrm{Mn}_{y} \mathrm{Te}(y \approx 0.2)$ crystal after RTA at temperatures $>600^{\circ} \mathrm{C}$. A $25 \%$ increase in $\Delta E$ (from $60 \mathrm{meV}$ to $75 \mathrm{meV}$ ) is observed when the implanted $\mathrm{O}$ dose doubles (from $2.7 \%$ to $5.4 \%$ ). The observed band gap reduction in $\mathrm{O}^{+}$synthesized $\mathrm{Cd}_{l-}$ ${ }_{y} \mathrm{Mn}_{y} \mathrm{O}_{x} \mathrm{Te}_{1-x}$ can be analyzed using the band anticrossing (BAC) model. In this work, however, the coupling element between the localized $\mathrm{O}$ states and the extended states, $C_{O M}$ (Eq. (1)) cannot be determined independently because a precise measurement of the fraction of $\mathrm{O}$ on the Te sublattice (i.e., $x$ ) is not possible.

Nevertheless, we can still use the BAC model to make a reasonable estimate of the value of $x$ in our implanted material. PL studies in ZnTe have shown that at doping concentrations, oxygen forms a localized level in the gap with an energy $E_{O}=2.0 \mathrm{eV}$ above the valence band edge. ${ }^{23}$ It has been shown previously that the energy of the oxygen level, $E_{O}$ is constant in the absolute energy reference. ${ }^{16}$ Therefore the known band offsets between $\mathrm{ZnTe}$ and CdTe can be used to estimate the composition dependence of this energy level with respect to the $\mathrm{Cd}_{1-y} \mathrm{Mn}_{y}$ Te valence band edge as $E_{O}$ $=1.9+0.59 y(\mathrm{eV})$. This means that the oxygen level is resonant with the conduction band in $\mathrm{Cd}_{1-y} \mathrm{Mn}_{y} \mathrm{Te}$ when $0<\mathrm{y}<0.5$. Using Eq. (1) one can extract the values of the parameter $C_{L M}^{2} x$ from the measured values of $\Delta E$. For example, the observed band gap reductions in $\mathrm{Cd}_{0.8} \mathrm{Mn}_{0.2}$ Te crystals can be explained with $C_{L M}^{2} x$ values of 0.016 and 0.018 for implanted $\mathrm{O}$ contents of 2.7 and $5.4 \%$, respectively.

Although $C_{O M}$ cannot be determined independently, it is believed that the magnitude of this matrix element depends on the electronegativity difference between the matrix anion elements. Since the electronegativity difference between $\mathrm{O}$ and $\mathrm{Te}$ is larger 
than that between $\mathrm{N}$ and As, we make a further assumption that $C_{O M} \approx 3.5 \mathrm{eV}$ $\left(>C_{N M}=2.7 \mathrm{eV}\right)$. With these assumptions, we estimate that the substitutional $\mathrm{O}$ content (i.e., $x$ ) in the $\mathrm{Cd}_{0.8} \mathrm{Mn}_{0.2} \mathrm{O}_{x} \mathrm{Te}_{1-x}$ alloys formed by $\mathrm{O}$-implantation to be $\sim 0.0013$ and 0.0024 for the low and high dose samples. This corresponds to an "activation" efficiency (i.e., implanted $\mathrm{O}$ ions occupying substitutional Te sites) of $\sim 5 \%$, similar to what we observed in the case of the $\mathrm{N}$-ion implantation synthesized $\mathrm{GaN}_{x} \mathrm{As}_{1-x}{ }^{17,19}$ The results are also consistent with the low solubility of $\mathrm{O}$ in II-VI alloys. In fact, in most bulk grown II-VI compounds, an upper limit of $\sim 10^{17} \mathrm{~cm}^{-3}$ of $\mathrm{O}$ can be incorporated. ${ }^{24}$

The incorporation of the implanted $\mathrm{O}$ atoms in the Te sublattice as a function of annealing temperature was also investigated. Figure 2 shows the PR spectra of $\mathrm{Cd}_{0.8} \mathrm{Mn}_{0.2}$ Te crystals as-grown and implanted with 5.4\% $\mathrm{O}$ after RTA in the temperature range of $400-725^{\circ} \mathrm{C}$. A gradual increase in the band gap reduction is observed as the RTA temperature increases. The dependence of $\Delta E$, which results from the amount of $\mathrm{O}$ substituted in the Te sublattice, on the RTA temperature is displayed in the inset of Fig.

2. The annealing temperature dependence of the $\Delta E$ values for the Ne implanted $\mathrm{Cd}_{0.8} \mathrm{Mn}_{0.2} \mathrm{Te}$ crystals are also plotted for comp arison. The low $\Delta E$ values for the $\mathrm{O}$ implanted samples at RTA temperatures $<600^{\circ} \mathrm{C}$ can be primarily due to implantation induced damage, similar to the Ne implanted samples. After annealing at temperatures higher than $600^{\circ} \mathrm{C}$ the increase in $\Delta E$ indicates an increase of $\mathrm{O}$ incorporation in the Te sublattice.

PR spectra from seven $\mathrm{Cd}_{1-y} \mathrm{Mn}_{y} \mathrm{O}_{x} \mathrm{Te}_{1-x}$ alloys formed by high dose $\mathrm{O}(5.4 \%)$ implantation and their corresponding as-grown $\mathrm{Cd}_{l-y} \mathrm{Mn}_{y} \mathrm{Te}$ crystals for a wide range of MnTe mole fraction, $0.2<y<0.64$ are displayed in Fig. 3. The data for the $\mathrm{O}^{+}-$ implanted samples are from that annealing treatment which produced the maximum $\Delta \mathrm{E}$ $\left(T_{R T A}=600-730^{\circ} \mathrm{C}\right.$, depending on y $)$. Significant band gap reductions can be observed in all of the $\mathrm{O}$-implanted $\mathrm{Cd}_{l-y} \mathrm{Mn}_{y} \mathrm{Te}$ crystals, indicating the formation of $\mathrm{Cd}_{1 \text { - }}$ ${ }_{y} \mathrm{Mn}_{y} \mathrm{O}_{x} \mathrm{Te}_{1-x}$ alloys throughout the range of $\mathrm{Mn}$ content studied. We note that there is a 
significant increase of $\Delta E$ and an associated increase of the line broadening for the $\mathrm{Mn}$ alloy compositions larger than about $60 \%$.

The room temperature band gap energies of the unimplanted and $\mathrm{O}$ implanted $\mathrm{Cd}_{1-y} \mathrm{Mn}_{y}$ Te samples are displayed in Fig. 4 as a function of $y$ for $0.1<y<0.64$. The known dependencies of the conduction band minima on the MnTe mole fraction and our

estimate of $E_{\mathrm{O}}$ on $y$ are also shown. Assuming that both $x$ and $C_{O M}$ are independent of $y$ a best fit of the measured band gap energies of the $\mathrm{O}$ ion synthesized $\mathrm{Cd}_{1-\mathrm{y}} \mathrm{Mn}_{\mathrm{y}} \mathrm{O}_{\mathrm{x}} \mathrm{Te}_{1-\mathrm{x}}$ alloys using the BAC model [Eq. (1)] for $y<0.55$ yields a $C_{L M}^{2} x$ value of 0.02 . This suggests that the active $\mathrm{O}$ in the $\mathrm{Cd}_{1-\mathrm{y}} \mathrm{Mn}_{\mathrm{y}} \mathrm{O}_{\mathrm{x}} \mathrm{Te}_{1-\mathrm{x}}$ crystals, $x \approx 0.002$ or $\sim 3 \times 10^{19} \mathrm{~cm}^{-3}$. As is seen in Fig. 4 the $E_{O}$ level falls below $E_{M}$ for $y>0.55$. This corresponds to a change in the nature of the lowest $\mathrm{CB}$ minimum from delocalized, band-like for $y<0.55$ to localized oxygen like at $y>0.55$. This transition is most likely responsible for the large increase of the PR line width observed in the samples with $y>0.55$.

\section{CONCLUSION}

In conclusion, we have successfully synthesized the $\mathrm{Cd}_{1-y} \mathrm{Mn}_{y} \mathrm{O}_{x} \mathrm{Te}_{1-x}$ highly mismatched alloys by $\mathrm{O}$ implantation in $\mathrm{Cd}_{l-y} \mathrm{Mn}_{y} \mathrm{Te}$ crystals. The $\mathrm{O}$-induced reduction of the fundamental band gap is well described by the anticrossing interaction between the localized states of $\mathrm{O}$ and the extended states of the conduction band of the matrix II-VI crystal. The results demonstrate the existence of a new, broad class of group II- $\mathrm{O}_{x}-\mathrm{VI}_{1-x}$ highly mismatched alloys with properties analogous to the extensively studied and practically very important III- $\mathrm{N}_{x}-\mathrm{V}_{1-x}$ materials. It is anticipated that, similar to III- $\mathrm{N}_{x}-\mathrm{V}_{l-}$ ${ }_{x}$ materials, the new alloys should exhibit novel properties and expand the range of possible applications of group II-VI materials. 


\section{ACKNOWLEDGEMENT}

This work was supported by the "Photovoltaic Materials Focus Area" in the DOE Center of Excellence for the Synthesis and Processing of Advanced Materials, Office of Science, Office of Basic Energy Sciences, Division of Materials Sciences under U.S. Department of Energy Contract No. DE-ACO3-76SF00098. The work at Purdue received support from National Science Foundation grant No. DMR 98-00858 and from Purdue University through the University Reinvestment Program. 


\section{REFERENCES}

1. M. Weyers, M. Sato and H. Ando, Jpn. J. Appl. Phys. 31, L853 (1992).

2. M. Kondow, K. Uomi, K. Hosomi, and T. Mozume, Jpn. J. Appl. Phys. 33, L1056 (1994).

3. W. G. Bi and C. W. Tu, J. Appl. Phys. 80, 1934 (1996).

4. K. Uesugi, N. Morooka, and I. Suemune, Appl. Phys. Lett. 74, 1254(1999).

5. J. F. Geisz, D. J. Friedman, J. M Olson, S. R. Kurtz, and B. M. Keyes, J. Cryst. Growth 195, 401 (1998).

6. W. Shan, W. Walukiewicz, K. M. Yu, J. Wu, J. W. Ager, E. E. Haller, H. P. Xin, and C. W. Tu, Appl. Phys. Lett. 76, 3251 (2000).

7. K. M. Yu, W. Walukiewicz, W. Shan, J. Wu, J. W. Ager III, E. E. Haller, H. P. Xin, and C. W. Tu, Appl. Phys. Lett.78, 1077 (2001).

8. M. Kondow, T. Kitatani, S. Nakatsuka, M. C. Larson, K. Nakahara, Y. Yazawa, M. Okai and K Uomi, IEEE J. Sel. Topics in Quantem Elect. 3, 719 (1997).

9. M. Kondow, T. Kitatani, M. C. Larson, K. Nakahara, K. Uomi and H. Inoue, J. Crystal Growth 188, 255 (1998).

10. D. J. Friedman, J. F. Geisz, S. R. Kurtz, D. Myers and J. M Olson, J. Cryst. Growth 195, 409(1998).

11. S. R. Kurtz, A.A. Allerman, E.D. Jones, J.M. Gee, J.J. Banas, and B.E. Hammons, Appl. Phys. Lett. 74, 729(1999).

12. W. Shan, W. Walukiewicz, J. W. Ager III, E. E. Haller, J. F. Geisz, D. J. Friedman, J. M. Olson, and S. R. Kurtz, Phys. Rev. Lett. 82, 1221(1999).

13. W. Walukiewicz, W. Shan, J. W. Ager III, D. R. Chamberlin, E. E. Haller, J. F. Geisz, D. J. Friedman, J. M. Olson, and S. R. Kurtz, in Photovoltaics for the $21^{\text {st }}$ Century, edited by V. K. Kapur, R. D. McDonnell, D. Carlson, G. P. Ceasar, A. Rohatgi (Electrochemical Society Press, Pennington, 1999) p. 190. 
14. D. J. Wolford, J. A. Bradley, K. Fry, and J. Thompson, in Proceedings of the $17^{\text {th }}$ International Conference on the Physics of Semiconductors, edited by J. D. Chadi and W. A. Harrison (Springer, New York, 1984) p. 627.

15. C. Skierbiszewski, P. Perlin, P. Wišniewski, W. Knap, T. Suski, W. Walukiewicz, W. Shan, K. M. Yu, J.W. Ager, E.E. Haller, J.F. Geisz, and J.M. Olson, Appl. Phys. Lett. 76, 2409 (2000).

16. W. Walukiewicz, W. Shan, K. M. Yu, J. W. Ager III, E. E. Haller, I. Miotlowski, M. J. Seong, H. Alawadhi, and A. K. Ramdas, Phys. Rev. Lett. 85, 1552 (2000).

17. W. Shan, K. M. Yu, W. Walukiewicz, J. W. Ager, E. E. Haller and M. C. Ridgway, Appl. Phys. Lett. 75, 1410 (1999).

18. K. M. Yu, W. Walukiewicz, W. Shan, J. Wu, J. W. Beeman, J. W. Ager III, E. E. Haller, H. P. Xin, and C. W. Tu, Appl. Phys. Lett. 78, 1077 (2001).

19. K. M. Yu, W. Walukiewicz, J. Wu,, J. W. Beeman, J. W. Ager III, E. E. Haller, W. Shan, X. P. Xin, C. W. Tu, and M. C. Ridgway, J. Appl. Phys 90, 2227 (2001).

20. M. J. Seong, H. Alawadhi, I. Miotkowski, A. K. Ramdas,and, S. Miotkowska, Phys. Rev. B62, 1866 (2000).

21. D. E. Aspnes, Surf. Sci. 37, 418 (1973).

22. The damage profiles in $\mathrm{Cd}_{1-\mathrm{y}} \mathrm{Mn}_{\mathrm{y}} \mathrm{Te}$ crystals created by $\mathrm{Ne}, \mathrm{Cl}$ and $\mathrm{O}$ ions were calculated by the TRIM software package.

23. M. J. Seong, H. Alawadhi, I. Miotkowski, A. K. Ramdas and S. Miotkowska, Phys. Rev. B 60, R16275(1999).

24. M. J. Seong, I. Miotkowski, and A. K. Ramdas, Phys. Rev. B58, 7734 (1998). 


\section{FIGURE CAPTIONS}

Figure 1 Photomodulated reflectance (PR) spectra of three low dose O-implanted $\mathrm{Cd}_{I \text { - }}$ ${ }_{y} \mathrm{Mn}_{y} \mathrm{Te}$ samples (with $\left.\mathrm{y}=0.01-0.19\right)$ after rapid thermal annealing (RTA) at $600^{\circ} \mathrm{C}\left(\mathrm{O}\right.$ imp.; $\left.600^{\circ} \mathrm{C}\right)$. PR spectra from the corresponding unimplanted $\mathrm{Cd}_{1-y} \mathrm{Mn}_{y} \mathrm{Te}$ crystals are also shown for direct comparison.

Figure 2 PR spectra of $\mathrm{Cd}_{0.8} \mathrm{Mn}_{0.2}$ Te crystals as-grown and implanted with $5.4 \% \mathrm{O}$ after RTA in the temperature range of $400-725^{\circ} \mathrm{C}$. The inset shows the dependence of $\Delta E$, on the RTA temperature. The values of $\Delta E$ for the $\mathrm{Ne}$ implanted $\mathrm{Cd}_{0.8} \mathrm{Mn}_{0.2} \mathrm{Te}$ crystals are also plotted for comparison.

Figure 3 A series of PR spectra of seven $\mathrm{Cd}_{1-y} \mathrm{Mn}_{y} \mathrm{O}_{x} \mathrm{Te}_{1-x}$ quaternaries for a wide range of MnTe mole fraction, $0.2<y<0.64$ formed by high dose $\mathrm{O}(5.7 \%)$ implantation and their corresponding unimplanted $\mathrm{Cd}_{l-y} \mathrm{Mn}_{y}$ Te crystals.

Figure 4. The room temperature band gap energies of the unimplanted and $\mathrm{O}$ implanted $\mathrm{Cd}_{1-y} \mathrm{Mn}_{y} \mathrm{Te}$ samples as a function of $y$ for $0.1<y<0.64$. The known dependencies of the conduction band minima on the MnTe mole fraction and our estimate of $E_{\mathrm{O}}$ on $y$ are also shown. The solid lines are the upper and lower subbands calculated by the BAC model using a $C_{L M}^{2} x$ value of 0.02 . 


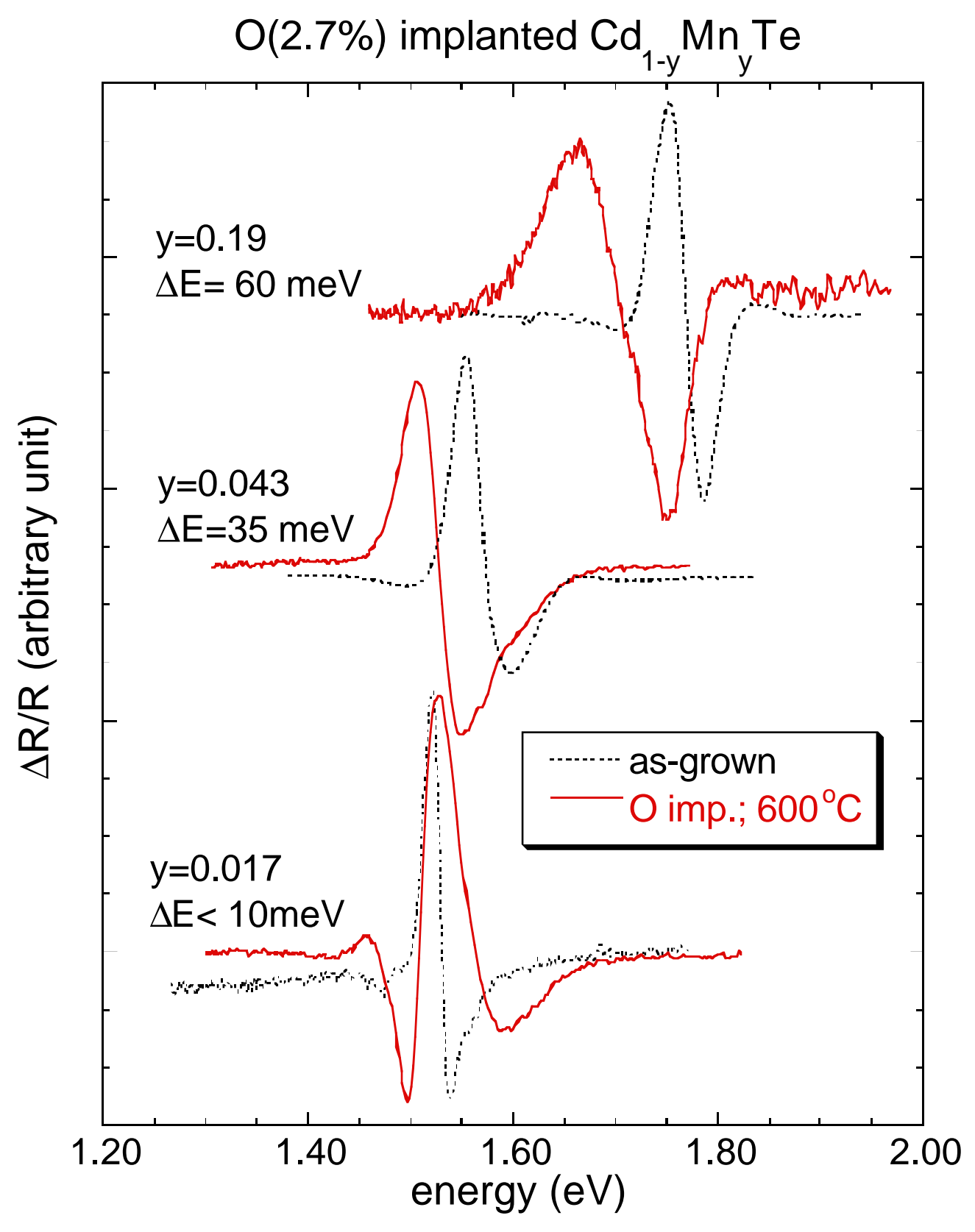

Fig. 1 


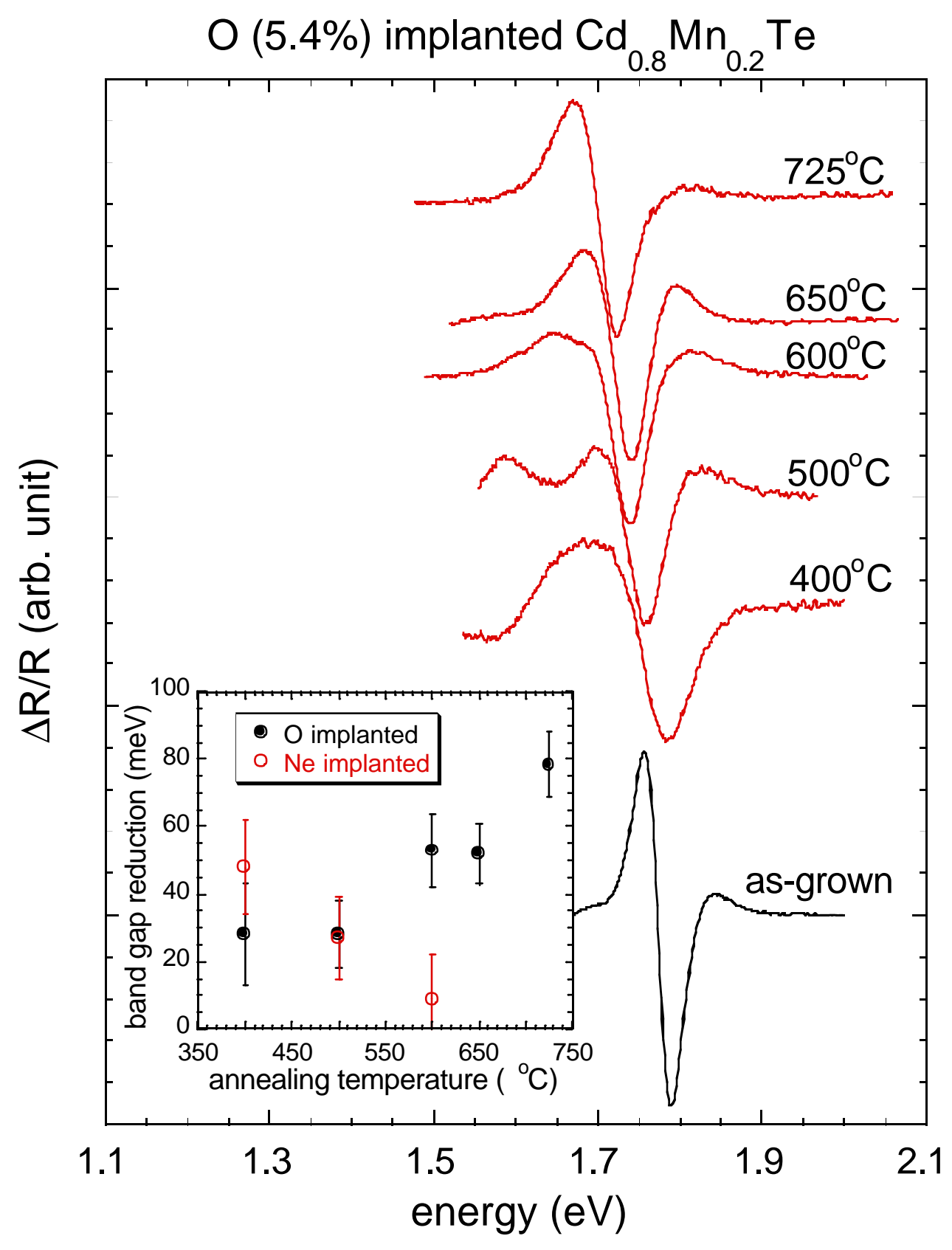

Fig. 2 


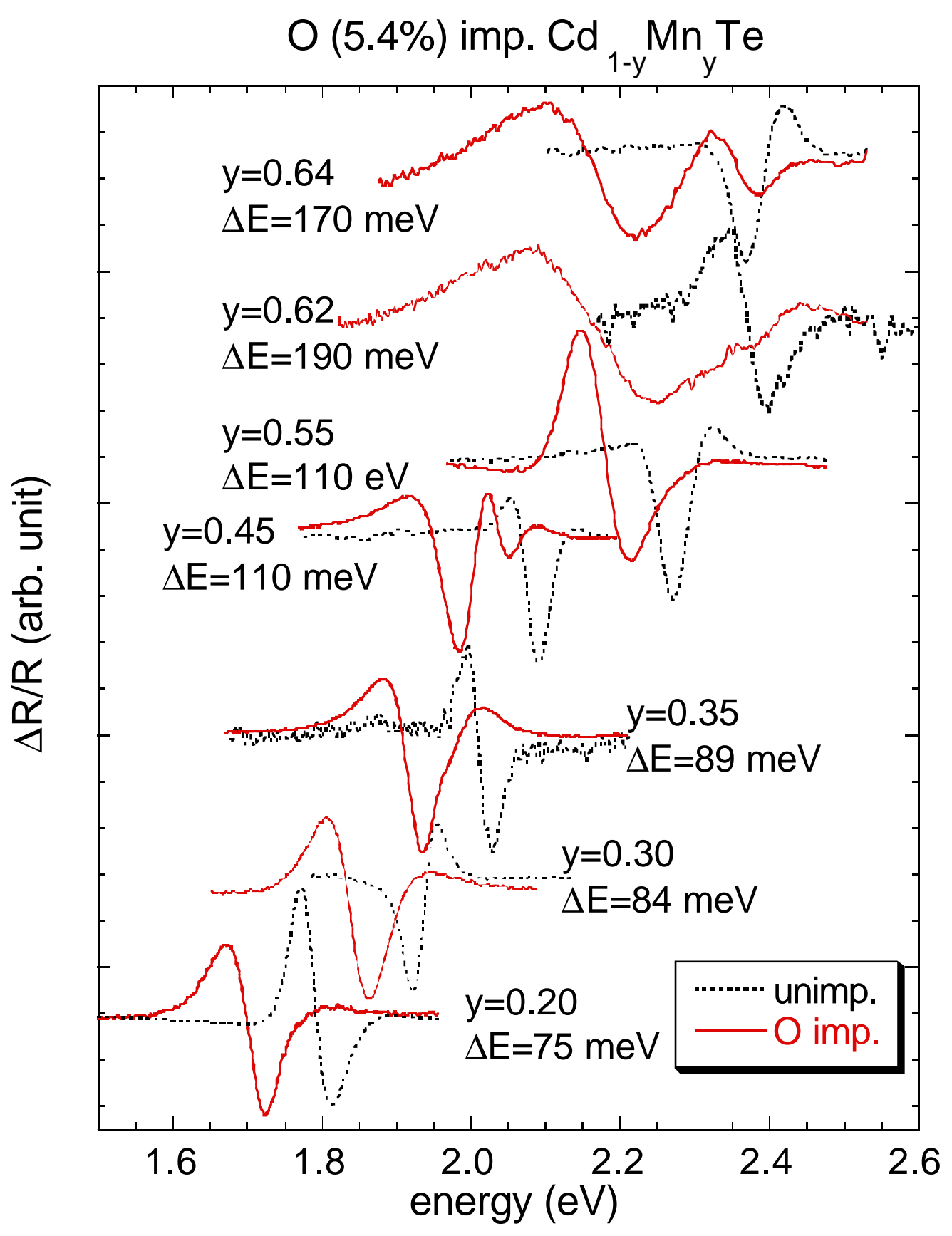

Fig. 3 


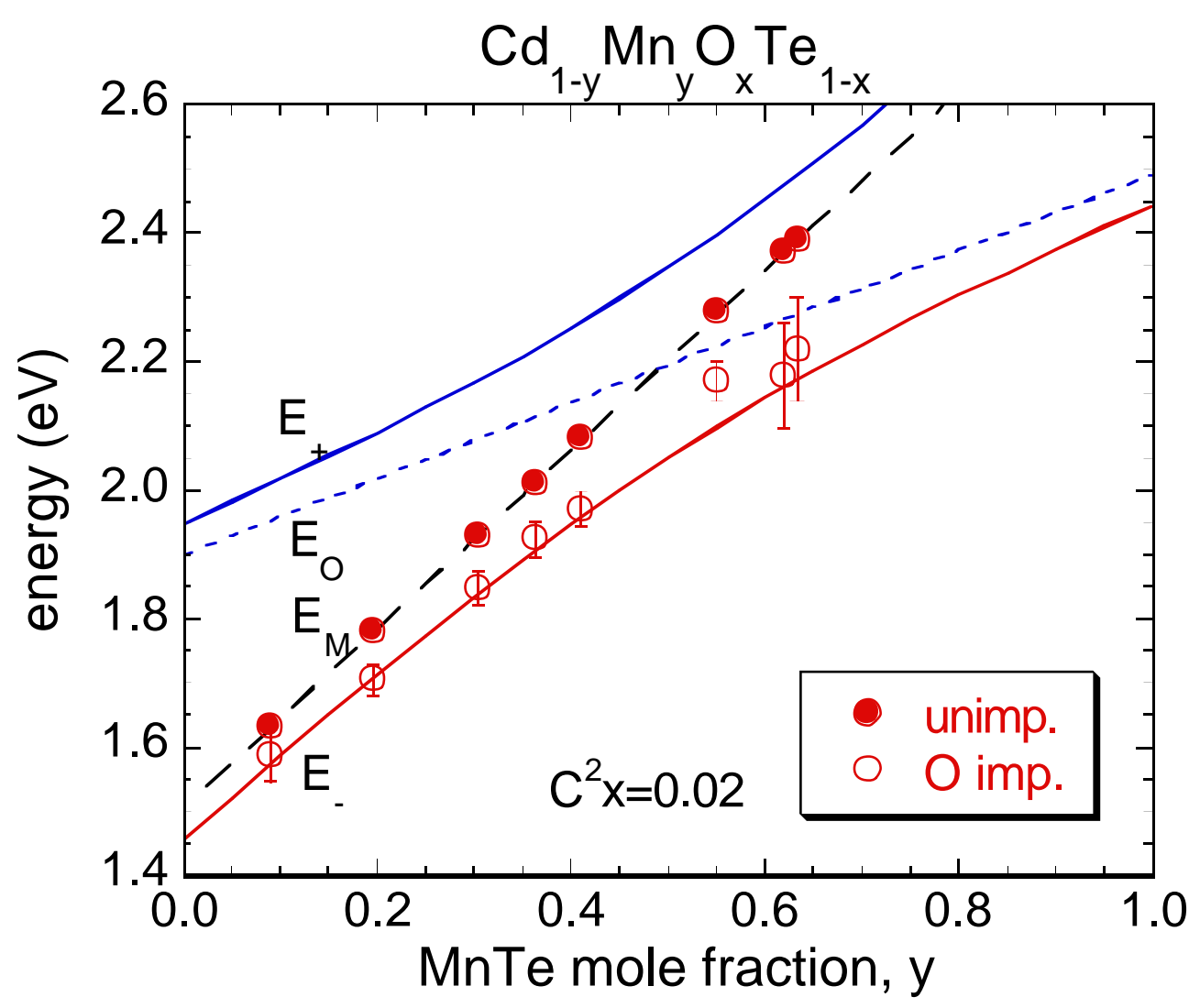

